\title{
Cost evaluation in design for end-of-Life of automotive components
}

\author{
Catherine Anthony ${ }^{1} \cdot$ Wai M. Cheung ${ }^{1}$ (D)
}

Received: 14 March 2017 / Accepted: 3 May 2017 / Published online: 10 July 2017

(C) Springer Science+Business Media Dordrecht 2017

\begin{abstract}
The European Union implemented the End-of-Life Vehicle directive to deal with an estimated 6 million end-of-life vehicles each year. Existing literature describe the processes to deal with the waste at end-of-life of different products but there is a lack of information on the costing of these options. These costs remain a concern to automotive manufacturers. This paper therefore reports the end-of-life costs of vehicle components and also demonstrates how these costs can be predicted at the design stage. The proposed approach should help to decide whether the automotive parts are viable for remanufacture, refurbishment, recycling, or disposal from an economic perspective. Two different automotive parts have been selected as case studies to validate the approach. Assumptions were made during the development of the technique and based on the results, the proposed approach could potentially provide vehicle manufacturers a method of estimating the cost of end-of-life recovery processes of vehicle components.
\end{abstract}

Keywords End-of-life vehicle $\cdot$ Remanufacture $\cdot$ Refurbish $\cdot$ Recycle $\cdot$ Disposal $\cdot$ ELV $\cdot$ EoL costs

\section{Introduction}

This paper reports the investigation of automotive manufacturers and suppliers have to face by meeting the requirements of End-of-Life Vehicle (ELV) legislation [1, 2]. ELV is the term when a vehicle comes to the end of its useful life, whether this is naturally due to wear and tear or prematurely (such as an accident) [3]. Mass production of cars is accountable for more than a million ELVs each year in the UK [4]. Production of cars has grown steadily over the past

Electronic supplementary material The online version of this article (doi:10.1007/s13243-017-0035-5) contains supplementary material, which is available to authorized users.

Wai M. Cheung

wai.m.cheung@northumbria.ac.uk

1 Faculty of Engineering and Environment, Department of Mechanical and Construction Engineering, University of Northumbria, Upon Tyne, Newcastle NE1 8ST, UK 
30 years to the point where in 2016 around 95 million were produced worldwide [5]. It had become necessary for legislation to put in place to ensure that automotive producers make their vehicles more sustainable [4]. The European Directive 2000/53/EC "ELV Directive" seeks to make dismantling and recycling of ELVs more environmentally friendly [1]. It is also used to regulate recycling procedure and the ratio of how much material should be recycled [6].

With automotive components, it is generally believed that costs occur throughout production and the product's life cycle. While manufacturers of course consider the costs of production, it is equally important that they consider the costs associated at End of Life (EoL), owing to ELV directive putting responsibility on the producer. Therefore, it is becoming increasingly important to consider the cost of disposal from the design stage to improve the efficiency in EoL. Xu et al. [7]; Cheung and Pachisia [8] state that a factor in the accomplishment of production and delivery of function need is cost. To be more competitive, manufacturers will need to consider many factors whilst also reducing costs.

Disregarding EoL costs would make it easier to meet requirements specified by legislation, as it is possible to recycle virtually $100 \%$ of an ELV. Economically this would be unreasonable, as it could be unprofitable to the Original Equipment manufacturers (OEMs). EoL costs consist of creating, operating, maintaining, replacing, and then disposing of a product. The costs required to meet the ELV legislation will help the OEM to decide if a product is viable. The components of the ELV's are usually recycled, reused, remanufactured, disposed or a combination of these attributes. Each of these methods has a cost associated with them, therefore these costs will need to be factored into new vehicles as the manufactures are required to be directly responsible for the environmental impacts of their products.

Manufacturers have to take a more ethical approach to ensure components have been designed with the ability to be reused, recycled, recovered, and remanufactured. As part of this process it is essential to ensure that all vehicles can be easily de-polluted. The ELV legislation also requires that at the design stage, preventive measures are in place to reduce the use of hazardous substances to facilitate recycling [2]. Car manufacturers are under increasing pressure to accept responsibility for the complete life cycle of the vehicles they produced due to the implementation of government legislation. This requires a set of targets to be met for recycling, re-use and recovery. To confront with these targets, manufacturers have to prepare for EoL scenarios by considering them at the design stage. EoL is an important factor to be considered from the design stage as environmental impacts can be locked-in at this early stage. Therefore, this paper aims to demonstrate an approach to automotive manufacturers to estimate the end of life cost of a vehicle's components. Two automotive parts are used to validate the approach and the method could allow OEM to select the most cost effective way of dealing with ELV. The remainder of this paper is organised as follows: "Literature review" section describes the background literature; "The proposed end-of-life cost prediction method for ELV" section presents the proposed method; "Case studies" section discusses the relevant case studies and finally the conclusion and future work are presented in "Conclusion and further work" section.

\section{Literature review}

The finding of the industrial survey by Cheung et al. [9] identified that about half of the cost for the life cycle of a product is usually associated with the manufacturing and in-service stages. They concluded that the EoL cost of a product is the least concerned to OEMs. 
However, according to EU's legislations [10] the consideration of end-of-life of a product is becoming very critical for OEMs in order to meet the target of reducing the amount of waste.

Legislation for waste disposal was introduced due to an increased environmental awareness and the ever-decreasing lack of landfill space [1]. Anderson et al. [11] predict that growth of ELVs from 2005 to 2030 will have a significant increase of nearly $50 \%$. Vermeulen et al. [12] describe how most developed countries have introduced legislation to make re-use, recovery, and recycling mandatory and that member states must establish a collection system for ELV's. They state that the EU Directive aims to prevent vehicle waste by reducing hazardous substances, designing with disassembly, re-use and recycling in mind, and increasing the use of recyclable materials. The EU-Directive states that by 2006 [13], at least $85 \%$ reuse and recovery and $80 \%$ re-use and recycling must be achieved, and these targets were set to rise in 2015 to $95 \%$ and $85 \%$ [12].

It is reported that every year around 8-9 million tonnes of waste is generated due to ELV's [2, 14]. The EU directive was established to encourage the reduction of waste. The directive aims to reduce the environmental impact of ELV by promoting re-use, recycling, and recovery. This initiative forces the automotive manufacturer to take responsibility for its product's disposal and by doing so, encourages manufacturers to make their products more sustainable. The ELV directive states that no more than $5 \%$ of a vehicle can be sent to landfill, leaving the remainder to be recycled or re-used. Data from 2014 [15] revealed that waste sent to landfill was cut by a third in a year to achieve an all-time low.

The Society of Motor Manufacturers and Traders (SMMT) [15] state that the EU recycling and recovery targets require $95 \%$ of ELV's to be recycled and recovered. As a result, industries are developing better strategies for coping with the waste. Vehicle scrapping over the past 4 years has fallen from 2.1 million per year between 2003 and 2009 to almost 1.85 million per year [15]. EoL treatment, recovery, and recycling are ultimately an OEM's responsibility, therefore they need to design their products in a way that minimises or eliminates environmental impact or makes the product easier to recycle at end-of-life [16, 17]. Gonzalez and Adenso-Diaz [18] mentioned the five alternatives such as disposal, recycling, reuse, repair, or remanufacturing for a product at end-of-life. They state that reuse, remanufacturing and repair are the better options for their environmental impact. However, they are not necessarily the best options due to the high cost associated with them [18].

Recycling would be a more viable option if disassembly cost was not so expensive. If products were designed with dismantling in mind then this would lower the EoL cost but this in turn may increase production costs. Das et al. [19] discussed that disassembly is gradually becoming more widespread and frequently used in industry. They suggest several reasons for this, including:

- retrieving valuable and reusable vehicle parts,

- separation processes which allow for downstream material recovery,

- hazardous and toxic materials removed,

- remanufacturing to elongate lifespan, and

- to break up the proprietary components.

They pointed out that at the very least, disassembly reduces the need for disposing into landfill [19]. 
Thierry et al. [20] declare that from the design stage, OEMs need to consider different materials, their value, their environmental impacts, and the way the components and materials are assembled [21]. To achieve a more sustainable automotive production, OEMs will need to consider design for sustainability which involves economical, social, and ecological aspects. Mcauley [22] states that automotive manufacturers need to consider the product's entire life cycle and its overall environmental impact during the design stage. To reduce or remove the impact they can minimise materials of concern and integrate design for recycling, disassembly, and reuse. To ensure long term sustainability, energy consumption and environmental impact must be greatly reduced during the life cycle. Keoleian and Menerey [23] promote a systematic approach to reduce environmental impact using life cycle design. This method balances environmental impact with satisfying customer needs.

Hatcher et al. [24] confirm that 'remanufacturing' can often be considered an environmentally sustainable product end-of-life solution. Remanufacturing means the life of a product is extended and the product does not end up in landfill too soon [25, 26]. Reuse is considered environmentally friendly due to its goal of preserving resources and energy. Environmentally, repair and remanufacturing are a good option as they extend a product's life. To ensure life-cycle longevity, OEMs should design their products to allow the user to be able to look after and maintain them. Design for disassembly means that vehicle's parts can be easily removed to repair or replace which makes maintenance easier. Overall, cost is an important factor whilst designers have to comply with ELV legalisation, they should also consider the costs associated to a component once it has reached the end of its life at the design stage.

\section{The proposed end-of-life cost prediction method for ELV}

As suggested by Cheung et al. [9]'s finding, most companies do not consider EoL costs in design. However the design stage is very crucial as a product's impact is often 'locked in' at this stage. By developing a cost estimation method to predict products EoL costs at the design stage, this will help product designers to consider the economic aspect. The scope of this section therefore discusses the different EoL options in terms of cost.

Reuse is often the first option manufacturers consider. Reuse would provide the most costeffective method due to no cost for additional processes. This is not always possible as EoL parts tend not to be in a usable condition without requiring rework. In accordance with the literature's finding the main EoL options are (i) recycling; (ii) remanufacturing; (iii) refurbishing and (iv) disposal as illustrated in Fig. 1. The method is based on Gonzalez and Adenso-Diaz [18]'s approach in "Product life cycle and end of life cycle". The following sections examine how each of these cost options is formulated.

\section{Product end-of-life cost prediction}

With increasing environmental awareness within the EU, several directives such as Waste Electrical and Electronic Equipment (WEEE); Restriction of Hazardous Substances (RoHS) and the ELV have been implemented to reduce the quantity of waste and toxic materials and increase its re-use, recovery and recycling [10]. Manufactures are effectively being forced to minimise their environmental impact when creating products. To achieve this, design for disassembly (DFD) is necessary. DFD is the consideration of easing disassembly to allow 


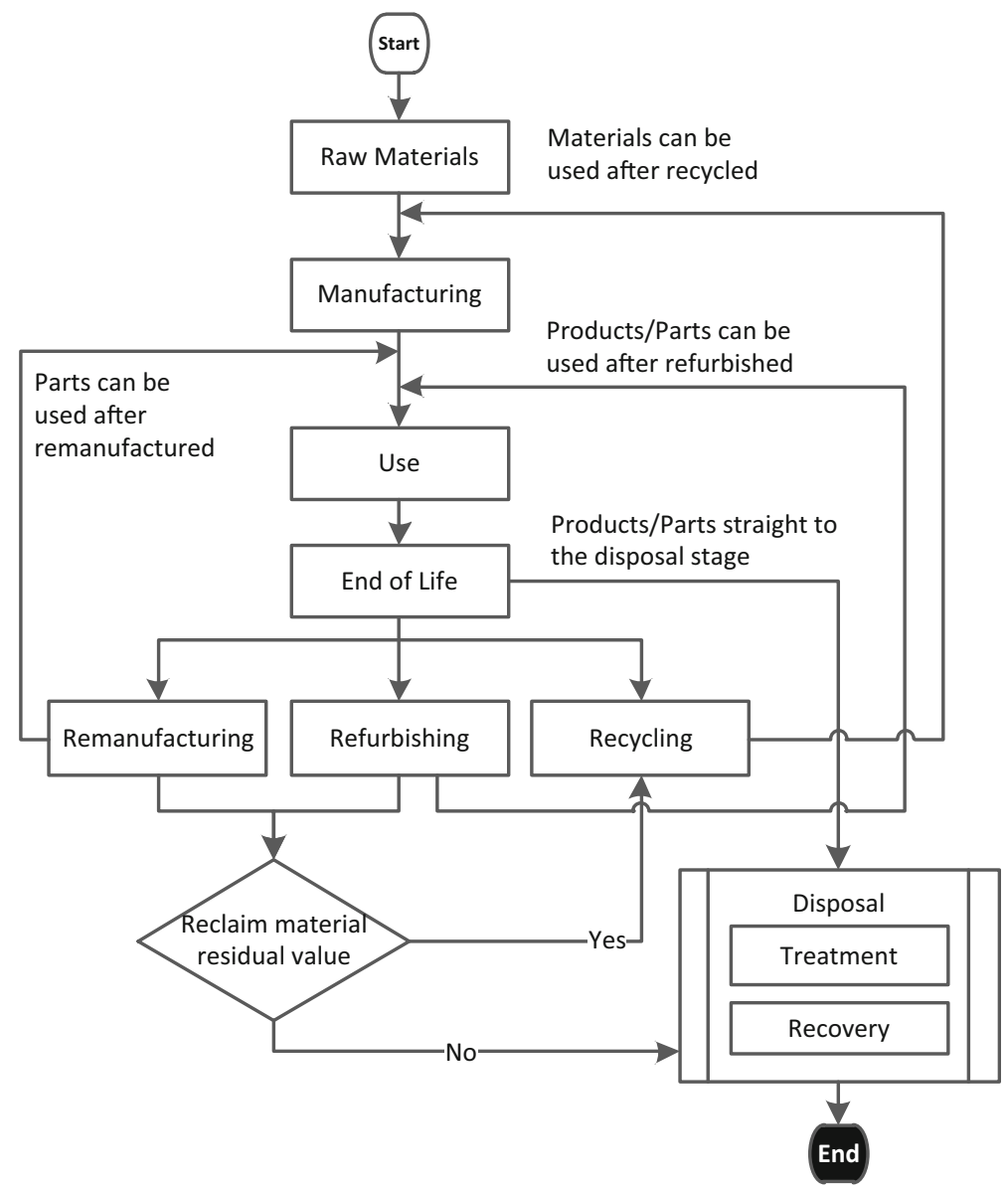

Fig. 1 The proposed method of processing ELV cost options (Adopted from Gonzalez and Adenso-Diaz [18])

for a product to be easily dismantled at EoL and this will allow for ease of re-use, recycling, and remanufacture [27-30]. Disassembly allows components and materials to be broken down into individual parts. There are two types of disassembly [30]:

(i) Non-destructive disassembly is the systematic process of removing parts from an assembly whilst ensuring that no damage occurs as a result of the process.

(ii) Destructive disassembly involves separating materials for recycling.

Bogue [27] mentions the factors that affect disassembly should be considered. Bogue concludes by saying that DFD allows manufacturers to comply with legislation and produce more cost-effective, environmentally friendly products. Disassembly is difficult to calculate as various factors can affect the result, such as; component complexity, fastening methods, part fragility, wear resistance, and ease of identification and handling. Disassembly depth factor proposed by Cheung et al. [9] made an assumption that all assemblies will take the same time to disassemble. The use of the disassembly depth factor measures how complicated a part is to disassemble, which is important to consider when estimating disassembly costs. 
For calculating the disassembly depth factor:

$$
f=\frac{\text { Number ofassemblies to disassemble }}{\text { Total Number of Assemblies }}
$$

This is based on the following assumptions and details:

- each assembly can be disassembled in the same time,

- disassembly divides an assembly into fundamental components and low-level assemblies,

- the time for individual component separation equals the disassembly time for the whole assembly,

- model treats as a component when entire assembly is targeted.

However, this is not a realistic assumption. For example, when considering a component fixed with 50 screws against one fixed with quick joints, and then quick joints will be easier and faster to disassemble. Situations like this make it difficult to devise a method for calculating disassembly which can be used across various components.

\section{Recycling}

Yan et al. [31] state that the process of recycling involves recovering used components and materials to use as raw materials. This definition is also supported by the ELV directive in that "recycling means reprocessing in a production process of the waste materials for the original purpose or for other purposes [32]". The associated costs that need to be considered for recycling are: disassembly, cleaning, and recycling (material processing, manufacturing, packaging, and assembly). It is believed that 75\% of ELV's are made of metals [33] which is the material that is mostly recycled at EoL. Other materials such as plastics and rubber will have to be considered too. Sakai et al. [34] discussed how recycling of Automotive Shredder Residue (ASR) is difficult due to the complexity of separating the materials; in particular the hazardous waste. During the design stage, manufacturers should look to reduce the number of materials and consider the environmental impact to make EoL manageable. For recycling option the proposed method has adapted Dantec's approach [35] of calculating recycling cost. In this cost model:

(i) recycling cost is defined as the amount of money to invest to remove targeted parts;

(ii) $\mathrm{RV}_{\mathrm{i}}$ represents the removal value of targeted parts; and

(iii) $\mathrm{RC}_{\mathrm{i}}$ represents the removal cost of targeted parts.

$$
\begin{gathered}
\text { Recycling Cost }=\Sigma\left(\mathrm{RV}_{\mathrm{i}}-\mathrm{RC}_{\mathrm{i}}\right) \\
\mathbf{R V}_{\mathbf{i}}=\Sigma\left(\left(\text { Parts }_{\mathrm{i}} \times \mathrm{MV}_{\mathrm{m}}-\mathrm{OC}_{\mathrm{i}}\right) \times \mathrm{W}_{\mathrm{i}}\right) \\
\mathbf{R C}_{\mathbf{i}}=\Sigma\left(\mathrm{RT}_{\mathrm{i}} \times f \times \mathrm{L}\right)
\end{gathered}
$$

Where:

Parts $_{i}$ the number of parts of type i

$\mathrm{W}_{\mathrm{i}}$ the weight of parts of type $\mathrm{i}(\mathrm{kg})$ 
$\mathrm{MV}_{\mathrm{m}}$ the mass material value of parts $(\mathfrak{f} / \mathrm{kg})$

$\mathrm{RT}_{\mathrm{i}} \quad$ the time necessary to remove one type $i$ part (hr)

$\mathrm{L}$ the hourly wage $(£ / \mathrm{hr})$

$\mathrm{OC}_{\mathrm{i}} \quad$ opportunity cost $(£ / \mathrm{kg})$. The opportunity cost corresponds to the revenue the dismantler would make by selling the parts to the shredder [35].

f disassembly depth factor

\section{Remanufacturing}

Ijomah et al. [36] state that "remanufacturing is a process of returning a used product to at least the original equipment manufacturer (OEM) performance specification from the customers' perspective and giving the resultant product a warranty that is at least equal to that of a newly manufactured equivalent". According to Ijomah et al. [37], remanufacturing can be both profitable and less harmful to the environment than conventional manufacturing as it reduces landfill and the levels of virgin material, energy and specialised labour used in production. Costs to be considered for remanufacturing are disassembly, cleaning, redesign and remanufacturing. Hatcher et al. [24] research shows that decisions made during the design process can greatly affect the remanufacturing process's 'efficiency and effectiveness'. To determine remanufacturing cost, the proposed method has adapted Shu et al. [38]'s approach of predicting the expense of remanufacturing. This adapted remanufacturing cost model however is focused on disassembly and assembly of a part or component using riveting. Costs associated with restoring of parts or components are excluded in the model. Further explanation of each of the expressions in eq. (5) can be found in reference [38] under section 8.25:

$$
\mathrm{C}_{\mathrm{RM}}=\left(\left(\mathrm{T}_{\mathrm{d}}+\mathrm{T}_{\mathrm{a}}\right) \times \mathrm{L} \times \mathrm{f}\right)+\left(\mathrm{P}_{\mathrm{f}} \times \mathrm{C}_{\mathrm{f}}\right)+\left(\left(\mathrm{P}_{\mathrm{pd}}+\left(\mathrm{P}_{\mathrm{f}} \times \mathrm{P}_{\mathrm{pe}}\right)-\left(\mathrm{P}_{\mathrm{pd}} \times \mathrm{P}_{\mathrm{f}} \times \mathrm{P}_{\mathrm{e}}\right)\right) \times \mathrm{C}_{\mathrm{p}}\right)
$$

Where

$\mathrm{C}_{\mathrm{rm}} \quad$ remanufacture cost $(£)$

$\mathrm{T}_{\mathrm{d}} \quad$ disassembly time (hr)

$\mathrm{T}_{\mathrm{a}} \quad$ assembly time (hr)

L labour rate $(£ / h r)$

f disassembly depth factor

$\mathrm{P}_{\mathrm{f}} \quad$ probability of fastener failure in disassembly and assembly

$\mathrm{C}_{\mathrm{f}} \quad$ cost of fastener failure (£)

$\mathrm{P}_{\mathrm{pd}} \quad$ probability of part failure in disassembly and assembly

$\mathrm{P}_{\mathrm{pe}} \quad$ probability of part failure in fastening method extraction

$\mathrm{C}_{\mathrm{p}} \quad$ cost of part failure (f)

\section{Refurbishing}

Refurbishing is an important part of the manufacturing process. It ensures that those re-usable components are as capable as new components. Whether the components have failed or not, they will be targeted for refurbishment. If the target component is in good condition at its EOL then a relatively minor refurbishing cost would be incurred e.g. cleaning. In contrast, a failed target component will incur higher refurbishing costs such as repair, replacement, etc. and the 
likely cost to refurbish is according to component failure/degradation rate data [39]. In order to determine refurbishing cost, the proposed method has adapted Zhou et al. [39]'s cost model as shown in eq. (6):

$$
\mathrm{C}_{\text {Refurbish }}=\Sigma\left(\mathrm{C}_{\text {good }}{ }^{\mathrm{e}-\lambda \mathrm{t}}+\mathrm{C}_{\text {failure }}{ }^{\left(1-\mathrm{e}^{-\lambda t}\right)}\right)+\mathrm{f} \times \mathrm{L} \times\left(\mathrm{T}_{\mathrm{d}}+\mathrm{T}_{\mathrm{a}}\right)
$$

Where:

$\mathrm{C}_{\text {good }} \quad$ cost to refurbish a target part/component in good condition (£)

$\mathrm{C}_{\text {failure }} \quad$ cost to refurbish a target component has failed (£)

$\mathrm{t} \quad$ expected lifetime of product (usually per million depends on degradation rate $\lambda$ )

$\mathrm{T}_{\mathrm{d}} \quad$ time to completely disassembly product (hr)

$\mathrm{T}_{\mathrm{a}} \quad$ time to completely assembly product (hr)

f disassembly depth factor

L labour rate $(£ / \mathrm{hr})$

$\lambda \quad$ degradation rate (failure per million $\mathrm{hr}$ )

\section{Implementation}

Microsoft Visual Basic was used to develop the software program. A user interface has been created as shown in Fig. 2. and this will to allow a designer to incorporate ELV costing into the design process to compare EoL options to understand which the most economical option for the targeted components is. To decide which EoL option to pursue, the designer will need to

Fig. 2 The GUI of EoL cost evaluations

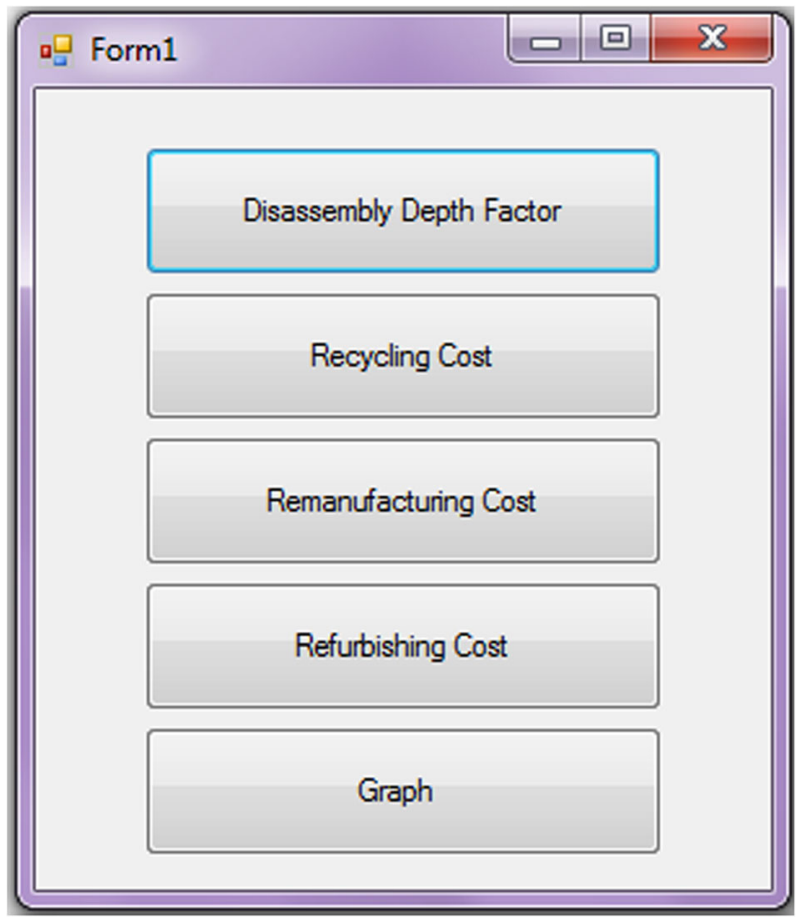


execute the software by selecting all options individually so that a comparison of EoL costs can be performed. The relevant source code of the software system is shown in Appendix A.

\section{Case studies}

Two case studies are used to validate the approach and the chosen vehicle components are (i) a registration plate lamp light and (ii) a brake pad. These two components are made of different materials and manufacturing methods.

\section{Registration plate lamp light}

Fig. 3 illustrates a 'registration plate lamp light', when it reaches the end of its life, the light can no longer illuminate the number plate or if the light becomes too dull. To ensure the light is bright enough, the upper polymer housing is made of polycarbonate. It also has a very high impact resistance which is an important factor when designing these components to be used on the external of a car. The lower housing of the light is made of polypropylene which only absorbs minimal water and has low permeability. There is also a rubber seal inside the housing to prevent water from entering. Once it has reached the end-of-its useful life, and evaluation of its EoL is represented by the flow chart as shown in Fig. 4.

The registration plate lamp light consists of 5 components that require disassembly so the disassembly depth factor can be calculated as shown in Fig. A1 Appendix B. By taking the disassembly depth factor into account of, the following EoL costs can be determined.

- EoL Option 1 - Remanufacturing cost

The whole part can be remanufactured for reuse. The fasteners are snap-fits which can easily be separated. With constant use they can become fatigue and fail. Therefore possibility

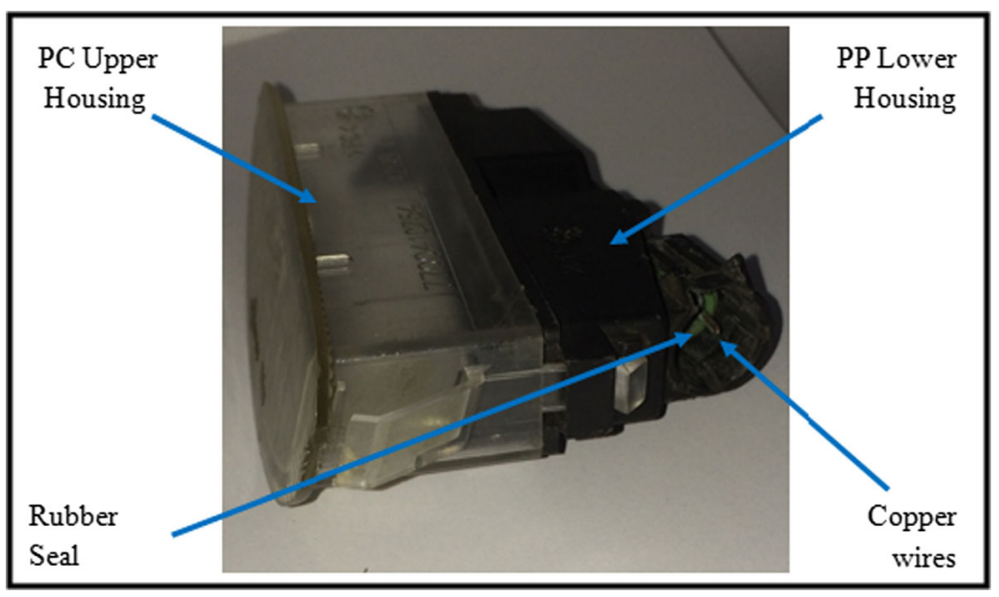

Fig. 3 A vehicle's registration plate lamp light 


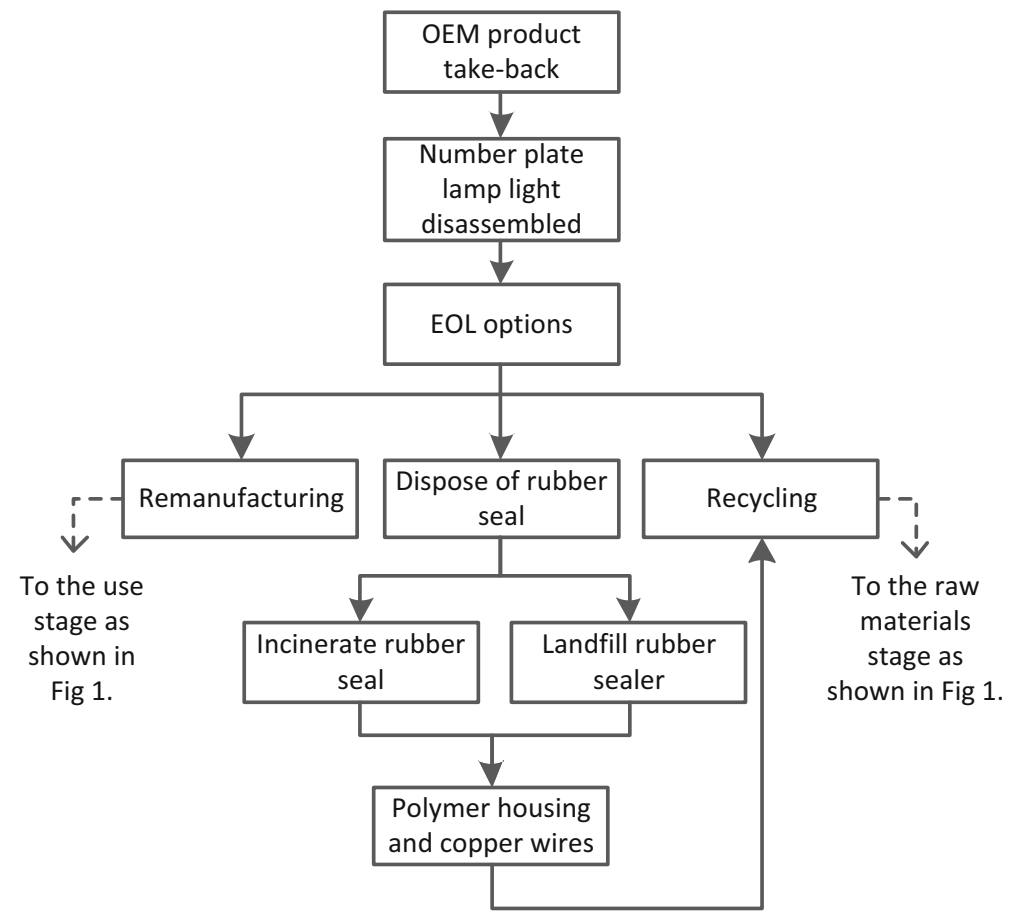

Fig. 4 EoL process of a vehicle's registration plate lamp light

of fastener failure is relatively high. Remanufacturing cost can be calculated as shown in Fig. A2 (Appendix B).

- $\quad$ EoL Option 2 - Recycling cost

As seen in Appendix B, Fig. A3, A4 and A5 illustrate recycling evaluations of three different sub-components and materials of the vehicle's number lamp light. Recycling all the components would be a low cost for the OEM as each individual material has a low cost to compare with remanufacturing.

- Compare EoL costs of the registration plate lamp light (Fig. 5.):

- Option 1 represents remanufacturing of the whole part.

- Option 2 represents recycling the whole part.

- Option 3 was not calculated as this component cannot be refurbished.

Fig. 5 shows that recycling is the optimum option for the EoL of the registration plate lamp light because it's cheaper than remanufacturing.

\section{Car's brake pad}

The second case study is a brake pad as shown in Fig. 6. Brake pads are used to convert a car's kinetic energy into thermal energy using friction. Brake pads operate under increasing 


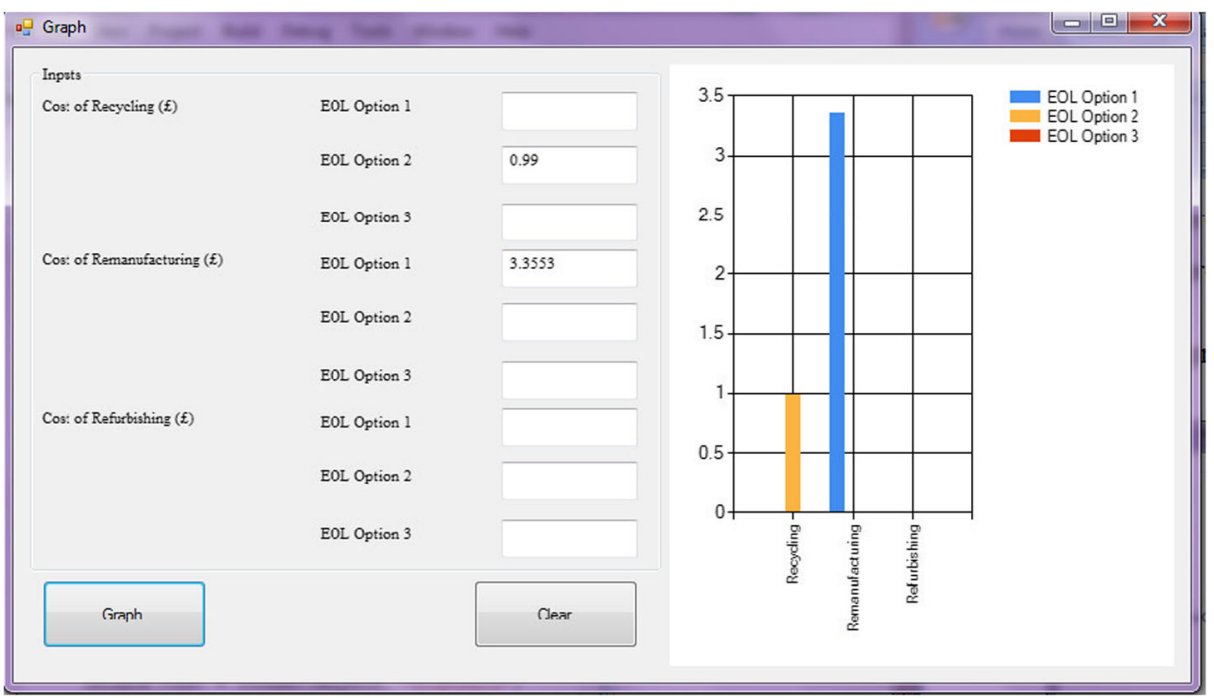

Fig. 5 Registration Plate Lamp EoL cost comparison

temperatures. Therefore they need a high resistance to heat and must be able to recover quickly from extreme heat application. The material needs to be smooth to provide even contact with the rotor. The brake pad is semi-metallic and is made of a mix of synthetics and flaked metals bonded together by various resins. These materials make it hard and resistant to wear. The shim is a thin layer of metal used to reduce brake noise caused by imperfections. The aluminium shim is riveted onto the steel base plate and an adhesive is used to join the pad to the plate. Once a brake pad becomes unsafe to continue using, then it can be considered at the end of its useful life. Fig 7 represents the EoL options of brake pads when they reached the end-of-their-useful life.

The part is made up of 5 components; two rivets, steel base plate, aluminium shim, and semi-metallic brake pad, so the disassembly depth factor can be calculated as shown in Appendix B Fig. A6. By taking the disassembly depth factor into account of, the following brake pad's EoL costs can be determined.

\section{- EoL Option 1 - Remanufacture}

The brake pad and rivets cannot be remanufactured so that remanufacturing cost of the metal plates can be estimated as shown in Fig. A7 (Appendix B). The probability of fastener
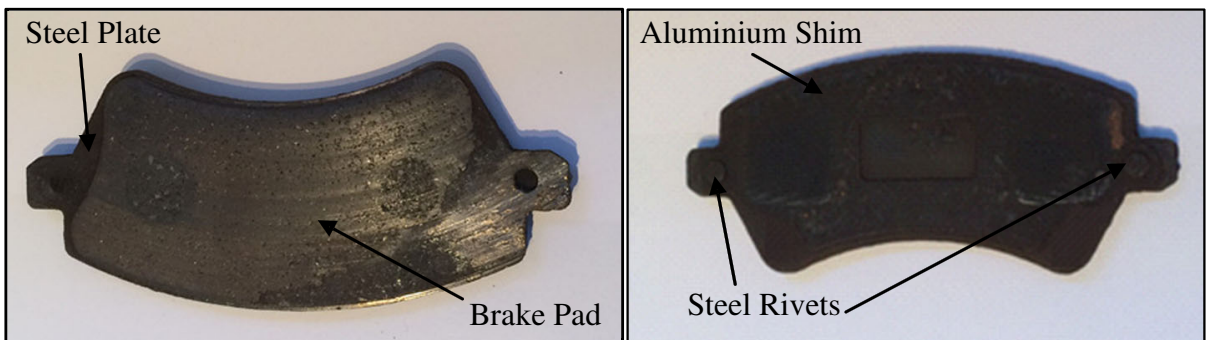

Fig. 6 A Semi-metallic brake pad 


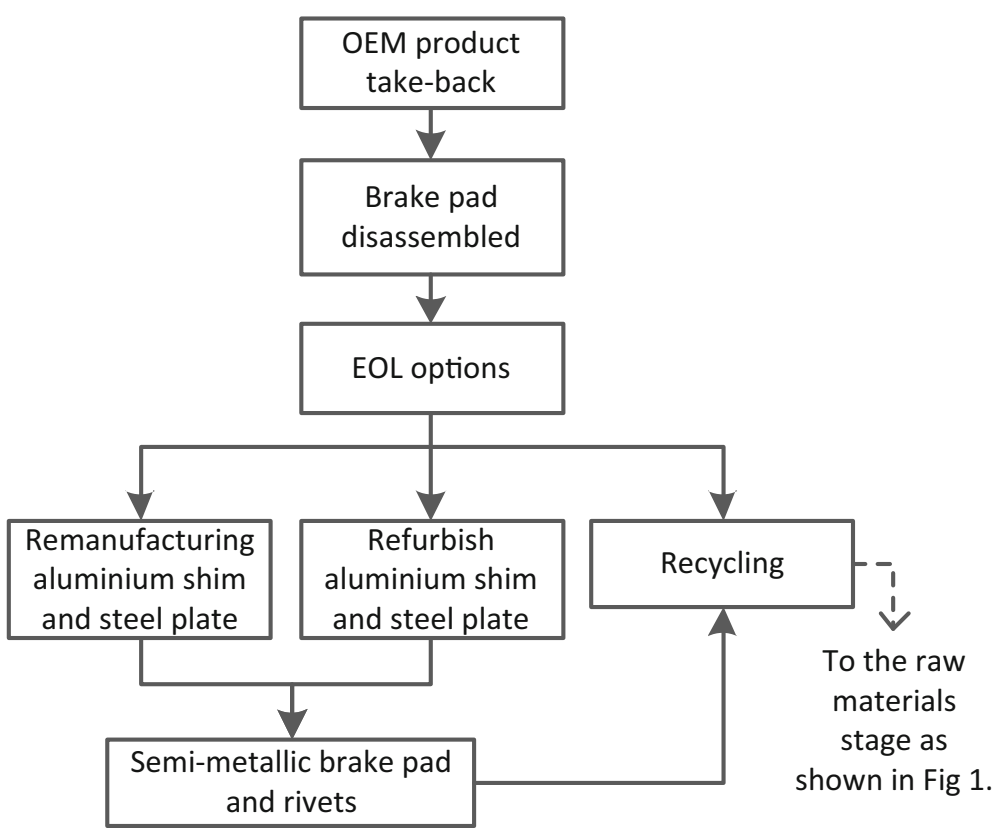

Fig. 7 EoL options of a brake pad

failure is $100 \%$ as the rivets must be drilled to disassemble the brake pad. The probability of part failure is low because the other components are strong and the number of fasteners is minimal.

\section{- EoL Option 2 - Refurbishing}

The brake pads and rivets cannot be refurbished but the metal plates can be reused. The degradation rate was obtained from Carnegie Mellon University [40]. This option looks already quite expensive for the OEM. The calculation of the refurbishing cost is shown in Fig. A8 (Appendix B).

- Recycling for EoL Options 1 and 2

The brake pad can be recycled for options 1 and 2, the cost of recycling for these two options are shown in Fig. A9 under Appendix B. This calculation shows that recycling the pad and rivets is least expensive.

\section{- $\quad$ EoL Option 3}

This option also gives a low recycling cost as shown in Fig. A10 (Appendix B)

Compare EoL costs of the brake pad, as seen in Fig. 8:

- Option 1 represents remanufacturing and recycling.

- Option 2 represents refurbishing and recycling.

- Option 3 represents all components are being recycled. 


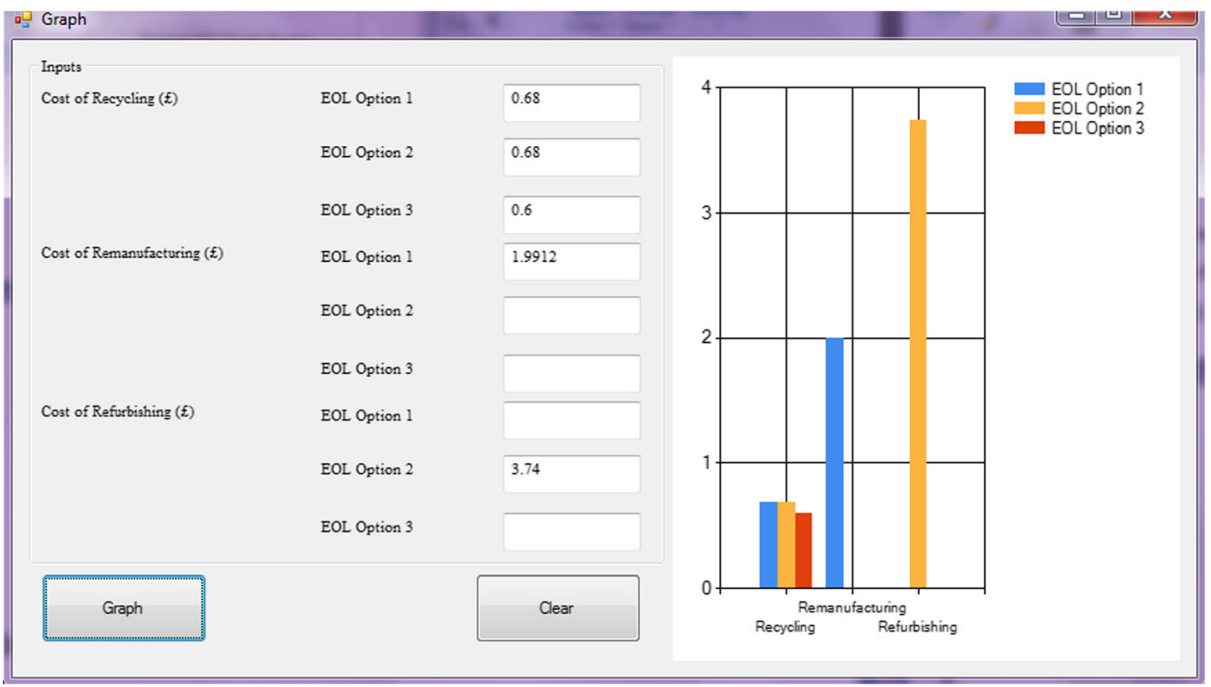

Fig. 8 A brake pad's EoL cost comparison

As seen in Fig. 8 that option 3 of recycling the whole component is an optimum solution as it works out significantly cheaper. It is also more ideal as it only requires one process whereas the other options require multiple processes.

\section{Conclusion and further work}

For the case study it would have been preferential to have had accurate and consistent data from one source to achieve a more reliable result for EoL costing analysis. However, as this was not possible, therefore assumptions were made based on different sources. This should give an approximate representation of the costs OEMs can expect to encounter at EoL.

The average retail price of the registration plate lamp light is £9. Any of the EoL options chosen would mean that around $50 \%$ of the retail price would cover EoL recovery cost. This indicates that there may have been over estimated. The proposed approach is also used estimated data for material value and opportunity cost. This will have led to a degree of inaccuracy. This implies that there have been inaccuracies in the values inputted into the software. It is possible that the average time of dismantling the part is unrealistically high as it was not dismantled by a trained labourer.

Due to cost, recycling appeared to be the optimum option for both parts. Realistically this might not be true as it is not necessarily the most economically-viable solution. Recycling adds no value to the product and its associated parts. Therefore it should only really be considered if the other options are not available. All of the EoL options point to disassembly being a major contributing factor to EoL cost. In the literature review, it was discovered that if disassembly was made easier then EoL costs could be reduced. To reduce costs, the following should be considered:

- $\quad$ Reducing the number of assemblies to speed up disassembly.

- Use simpler and less fastenings to reduce disassembly time and fastening failure. 
- Using fewer materials within components.

- Automate the disassembly process.

These options should only be considered if they do not affect quality, safety and functionality of the product.

To increase the accuracy of the estimations, a more comprehensive view of disassembly is needed. The disassembly depth factor in this study simplifies the time taken for disassembly and does not take into account the amount of fasteners or complexity of the fasteners. Therefore a new method for calculating disassembly is needed to ensure the cost estimations are more accurate.

ASR, Automotive Shredder Residue; DFE, Design for Environment; DFD, Design for Disassembly; ELV, End-of-Life Vehicle; EoL, End-of-life; EU, European Union; GUI, Graphical User Interface; OEM, Original Equipment Manufacturer; RoHS, Restriction of Hazardous Substances; SMMT, Society of Motor Manufacturers and Traders; WEEE, Waste Electrical and Electronic Equipment

Acknowledgements This research received no specific grant from any funding agency in the public, commercial, or not for-profit sectors. The authors would like to express their gratitude to the anonymous reviewers for their constructive comments and suggestions.

Author's contributions WMC supervised CA in this research work and updated the literature. CA conducted the background research, data collection and implementation. Both authors prepared and approved this manuscript

\section{Compliance with ethical standards}

Competing interests The authors declare that they have no competing interests.

\section{References}

1. Directive 2000/53/E (2000) http://eur-lex.europa.eu/resource.html?uri=cellar:02fa83cf-bf28-4afc-8f9feb201bd61813.0005.02/DOC_1\&format=PDF

2. Ferrao P, Amaral J (2006) Assessing the economics of auto recycling activities in relation to European Union directive on end of life vehicles. Technol Forecast Soc Change 73(3):277-289

3. Lind S, Olsson D, Sundin E (2014) Exploring inter-organizational relationships in automotive component remanufacturing. J Remanuf 4(1):5

4. Eurostat (2014) http://ec.europa.eu/eurostat/statistics-explained/index.php/End-of-life_vehicle_statistics

5. OICA (2016) [http://www.oica.net/category/production-statistics/]

6. CIWM (2017) End of life vehicles fact file http://www.ciwm.co.uk/CIWM/InformationCentre/AtoZ/EPages /EndofLifeVehiclesFactFile.aspx

7. Xu Y, Elgh F, Erkoyuncu JA, Bankole O, Goh Y, Cheung WM, Baguley P, Wang Q, Arundachawat P, Shehab E, Newnes L (2012) Cost Engineering for manufacturing: current and future research. Int J Comput Integr Manuf 25(4-5):300-314

8. Cheung WM, Pachisia V (2015) Facilitating waste paper recycling and repurposing via cost modelling of machine failure, labour availability and waste quantity. Resour Conserv Recycl 101:34 41

9. Cheung WM, Griffin P, Newnes L, Mileham A, Marsh R, Lanham J (2015) Towards cleaner production: a roadmap for predicting product end-of-life costs at early design concept. J Clean Prod 87:431-441

10. EU Environmental Directives (2004) http://ec.europa.eu/environment/legal/liability/

11. Andersen F, Larsen H, Skovgaard M (2008) Projection of end-of-life vehicles: development of a projection model and estimates for ELVs for 2005-2030, ETC/RWM working paper 2008/2, Copenhagen 
12. Vermeulen I, Van Caneghem J, Block C, Baeyens J, Vandecasteele C (2011) Automotive shredder residue (ASR): reviewing its production from end-of-life vehicles (ELVs) and its recycling, energy or chemicals' valorisation. J Hazard Mater 190(1):8-27

13. Directive 2000/53/EC (2007) http://eur-lex.europa.eu/legal-content/EN/TXT/?uri=celex:52007DC0005

14. End-of-life vehicle statistics (2016) http://ec.europa.eu/eurostat/statistics-explained/index.php/End-of-life vehicle_statistics\#Total_number_of_end-of-life_vehicles

15. Society of Motor Manufacturers and Traders (SMMT), Automotive Sustainability Report- SMMT' 2014. [http://www.smmt.co.uk/2014/07/automotive-sustainability-report-2014/.]

16. Fukushige S, Yamamoto K, Umeda Y (2012) Lifecycle scenario design for product end-of-life strategy. J Remanuf 2(1):1

17. Schau EM, Traverso M, Finkbeiner M (2012) Life cycle approach to sustainability assessment: a case study of remanufactured alternators. J Remanuf 2(1):5

18. González B, Adenso-Díaz B (2005) A bill of materials-based approach for end-of-life decision making in design for the environment. Int J Product Res 43(10):2071-2099

19. Das SK, Yedlarajiah P, Narendra R (2000) An approach for estimating the end-of-life product disassembly effort and cost. Int. J. Product. Res. 38(3):657-673

20. Thierry M, Salomon M, Van Nunen J, Van Wassenhove L (1995) Strategic issues in product recovery management. Calif Manag Rev 37:2

21. Gallimore A, Cheung WM (2016) Effects of environmental impact based on alternative materials and process selection in automotive component design. J Ind Product Eng 33(5):321-338

22. Mcauley J (2003) Global sustainability and key needs in future automotive design. Environ Sci Technol 37(23):5414-5416

23. Keoleian G, Menerey D (1993) Life cycle design guidance manual, National Pollution Prevention Center, University of Michigan 62

24. Hatcher G, Ijomah W, Windmill J (2013) Integrating design for remanufacture into the design process: the operational factors. J Clean Prod 39:200-208

25. Paterson DA, Ijomah WL, Windmill JF (2017) End-of-life decision tool with emphasis on remanufacturing. J. Clean, Prod (in press)

26. Wang X, Chan HK (2013) An integrated fuzzy approach for evaluating remanufacturing alternatives of a product design. J Remanuf 3(1):1-19

27. Bogue R (2007) Design for disassembly: a critical twenty-first century discipline. Assem Autom 27(4):285-289

28. Favi C, Germani M, Luzi A, Mandolini M, Marconi M (2017) A design for EoL approach and metrics to favour closed-loop scenarios for products. Int J Sustain Eng 10(3):136-146

29. Go T, Wahab D, Rahman M, Ramli R, Azhari C (2011) Disassemblability of end-of-life vehicle: a critical review of evaluation methods. J Clean Prod 19(13):536-1546

30. Gupta SM, McLean CR (1996) Disassembly of products. Comput Ind Eng 31(1):225-228

31. Yan X, Gu P (1995) Assembly/disassembly sequence planning for life-cycle cost estimation, Manufacturing Science and Engineering, ASME, MED-2 (2)/Mh-3, (2): 935-956

32. Directive 2000/53/EC (2016) http://eur-lex.europa.eu/legal-content/EN/TXT/PDF/?uri=CELEX:02000 L0053-20130611\&qid=1405610569066\&from=EN

33. Scottish Environment Protection Agency (2007) End of life Vechicles (ELV's), National Waste Strategy Scotland

34. Sakai SI, Yoshida H, Hiratsuka J, Vandecasteele C, Kohlmeyer R, Rotter VS, Passarini F, Santini A, Peeler M, Li J, Oh GJ (2013) An international comparative study of end-of-life vehicle (ELV) recycling systems. J Mat Cycl Waste Manag 16(1):1-20

35. Dantec D (2005) Analysis of the cost of recycling compliance for the automobile industry. Thesis for a master of science in technology and policy. Massachusetts Institute of Technology (MIT). MIT, USA

36. Ijomah WL, McMahon CA, Hammond GP, Newman ST (2007) Development of robust design-forremanufacturing guidelines to further the aims of sustainable development. Int J Prod Res 45(18-19): 4513-4536

37. Ijomah WL, McMahon CA, Hammond GP, Newman ST (2007) Development of design for remanufacturing guidelines to support sustainable manufacturing. Robot Comput Integr Manuf 23(6): 712-719

38. Shu L, Flowers W (1999) Applications of a design-for-remanufacture framework to the selection of product life-cycle fastening and joining methods. Robot Comput Integr Manuf 15(3):179-190

39. Zhou M, Caudill R, Sebastian D, Zhang B (1999) Multi-lifecycle product recovery for electronic products. J Electron Manuf 9(01):1-15

40. Inacio C (1998) Mechanical reliability. Carnegie Mellon University http://users.ece.cmu. edu/ koopman/des_s99/mechanical/ 